\title{
Serum Glucose Level of Alloxan Induced Diabetic Rats Treated With Glutathione Complex
}

\author{
Ibrahim Ali Bukar $^{1^{*}} \quad$ Muhammad Ibrahim Usman ${ }^{2} \quad$ Abubakar Bilyamini Mu'azu² \\ 1.Department of Human Physiology, College of Medical Sciences, Yobe State University Damaturu, \\ P.M.B. 1144, Yobe. Nigeria \\ 2.Department of Medical Biochemistry, College of Medical Sciences, Yobe State University Damaturu, \\ P.M.B. 1144, Yobe. Nigeria
}

\begin{abstract}
Antioxidant plays an important role in preventing the progression of diabetes mellitus (DM) complications. This study was undertaken to evaluate the hypoglycemic effect of glutathione complex in Alloxan induced diabetic rats. Thirty albino rats (weighing 120-130g) were divided into six groups of five rats each: Group one serves as normal control, group two served as diabetic control while Group three, four and five were diabetic and administered with $2.4 \mathrm{mg} / \mathrm{kg}$ body weight, $3.6 \mathrm{mg} / \mathrm{kg}$ body weight and $4.8 \mathrm{mg} / \mathrm{kg}$ body weight respectively. All treatments were administered orally for 4 weeks on daily basis. Serum glucose level was measured at an interval of three days throughout the period of the experiment. Results obtained showed that administration of Glutathione Complex to diabetic rats caused a significant decrease $(\mathrm{p}<0.05)$ in serum glucose level compared to diabetic control. These results suggest that administration of Glutathione Complex to diabetic rats may help reverse the complications of diabetes mellitus.
\end{abstract}

Keywords: Alloxan, Diabetes, Glucose and Glutathione Complex

DOI: $10.7176 /$ ALST/84-03

Publication date: December $31^{\text {st }} 2020$

\section{Introduction}

The incidence of diabetes mellitus (DM) is prevalent over all parts of the world. It is also associated with reduced quality of life and increased mortality and morbidity factors. DM is a complex, progressive disease, which is accompanied by multiple complications. Diabetes mellitus is a multi-faceted metabolic disorder where there is increased oxidative stress that contributes to the pathogenesis of this debilitating disease. This has prompted several investigations into the use of antioxidants as a complementary therapeutic approach (mandrup-poulsen, 1998). Data collected from clinical studies indicate that majority of the diabetic patients die due to cardiovascular diseases and atherosclerosis, which accounts for about 8 to $10 \%$ of all diabetic deaths. The established relationship between DM and atherosclerosis has fuelled suggestion to search for antidiabetic drugs with beneficial effects in reducing the atherosclerotic process in diabetic patients (Hokanson, 2002). Hyperglycemia is attributed to the development of diabetic complications. Hyperglycemia leads to increase in oxidative stress due to the overproduction of free radicals and decreased efficiency of antioxidant defense system. It occurs particularly in patients with poor glycemic control (Wiernsperger, 2003). Oxidation of lipids, proteins and other macromolecules (such as DNA) occurs during the development of diabetes and its complication. To control the influx of free radicals, aerobic cells have developed an antioxidant defense system, which directly or indirectly scavenges free radicals or prevents their conversion to toxic products (IDF, 2013). The stability and capacity of antioxidant status during chronic diabetes seriously influences the outcome of the long-term complications caused by oxidative stress.

In 2004 the makers of glutathione complex embarked on a business plan to develop the company's most powerful product for supporting good immune function (and also skin lightening). Not only was this formula meant to be effective, but also safe for normal use. Though the idea was simple enough, the research and development to create such product was surprisingly extensive. Every possible factor was considered in creating this revolutionary proprietary formula. This Essentials Blend 1500mg contains: Glutathione, Alpha Lipoic Acid, Milk Thistle, L-Cysteine, Other ingredients: Hypermellose, Cellulose and Magnesium Stearate. After two years of tests and trials, it was finally available for the public in the fall of 2006. Since then, the R\&D Team has been continuously improving the formula and product line with new innovations making this glutathione complex the most advanced formula on the market today (Dermazone, 2014).

The ingredient in the Complex "Essential Glutathione Complex" has been clinically tested to provide maximum benefit. Glutathione complex restores the function of organs particularly the liver. This complex improves the overall health and well-being of the body. It boosts the energy level as it contains $\alpha$-lipoic acid in addition to high concentration of glutathione. Glutathione flushes the toxins that build up in the liver.

There were postulations that glutathione complex can also serves as anti-hyperglycemic agent and therefore alleviating the complications of diabetes mellitus. This research work aims at investigating the anti-hyperglycemic potentials of glutathione complex (gluatathione, L-cystein, $\alpha$-lipoic acid and milk thistle) using alloxan induced diabetic rats. 


\section{Materials and Methods}

\subsection{Experimental Animals}

Thirty (30) albino rats (weighting 120 to $130 \mathrm{~g}$ ) were purchased from the department of biological science, Bayero University Kano and they were housed in colony cages at an ambient temperature and relative humidity. The animals had free access to standard palletized grower feed and drinking water and the experiments was performed according to the principles of laboratory animal care.

\subsection{Sample Collection and Preparation}

Glutathione complex was purchased from Hasiya Bayero Hospital, Kano. 1500mg of the complex was dissolve in $100 \mathrm{ml}$ with water. The volume administered was calculated according to the relation.

Volume to be administered $\left(\mathrm{cm}^{3}\right)=$ weight of rat $(\mathrm{kg}) \times$ dose in $\mathrm{mg} / \mathrm{kg}(50 \mathrm{mg} / \mathrm{kg})$

Concentration of Alloxan Solution $(\mathrm{mg} / \mathrm{ml})$

\subsection{Induction of Diabetes}

A stoke solution of Alloxan was prepared by dissolving $1 \mathrm{~g}$ of the Alloxan in $100 \mathrm{ml}$ of water $(100 \mathrm{mg} / \mathrm{ml})$. After 8hours of fasting, the rats were weighed, Lying on its back, the animals were given single intraperitoneal injection of alloxan. The volume of Alloxan administered was determined by the weight of the rat according to the following relationship.

Volume to be administered $\left(\mathrm{cm}^{3}\right)=\underline{\text { weight of } \mathrm{rat}(\mathrm{kg}) \times \text { dose in } \mathrm{mg} / \mathrm{kg}(50 \mathrm{mg} / \mathrm{kg})}$ Concentration of Alloxan Solution $(\mathrm{mg} / \mathrm{ml})$

In order to assess the effect of alloxan and to chemically establish the diabetic condition, an incision was done in any of the four veins in the tail of the rats using a blade after $48 \mathrm{hrs}$ of induction. A sample of the rat venous blood was collected on a reagent strip for blood glucose level determination using a portable glucose analyzer. The level of serum glucose considered to be normal in rattus novergicus ranges from 50 to $135 \mathrm{mg} / \mathrm{dl}$. In this study, rats with glucose levels above $200 \mathrm{mg} / \mathrm{dl}$ were considered as having severe diabetes.

\subsection{Experimental Design}

A total of 30 rats were divided into six groups of five rats per group as follows; Group I: Normal Control

Group II: Diabetic control

Group III: Diabetic rats, administered with $2.4 \mathrm{mg} / \mathrm{kg}$ of glutathione complex

Group IV: Diabetic rats, administered with $3.6 \mathrm{mg} / \mathrm{kg}$ of glutathione complex

Group V: Diabetic rats, administered with $4.8 \mathrm{mg} / \mathrm{kg}$ of glutathione complex

Group VI: Diabetic rats, administered with $7.8 \mathrm{mg} / \mathrm{kg}$ of glutathione complex

The blood glucose level of all the rats was measured (from the tail) prior to induction of diabetes using alloxan. After 48 hours of induction, the blood glucose level of group II to VI was checked to confirm induction. The blood glucose level of all the groups was measured after every two days for a period of four weeks.

\section{Results}

From the animals subjected to diabetes induction, $73 \%$ developed severe diabetes mellitus; $20 \%$ developed mild condition; and the remaining 7\% died within the first week of follow up, probably due to acidosis. The animals showed the following signs of the condition: polydipsia (abnormal thirst), polyuria (increased urine volume), weight loss (due to lean mass loss), asthenia (weakness due to the inability to use glucose as a source of energy), dehydration (due to the animal's body attempt to get rid of the excess blood glucose as the normal process of storing glucose in the body cells is impaired).

Tablel present Fasting Blood Glucose Level (mg/dl) in alloxan induced diabetic rats before administration of Glutathione Complex, and at intervals of three days after oral administration of Glutathione Complex for four weeks. Blood glucose level of positive control was significantly higher than that of negative controls $(p<0.05)$ $48 \mathrm{hrs}$ after induction of diabetes. Four weeks after administration with Glutathione Complex, rats in groups III, IV, V and VI were found to have lower blood glucose level than groups II. The observed difference between the groups were significant $(\mathrm{P}<0.05)$. 
Table 1: Fasting Blood Glucose Level (mg/dl) in Alloxan Induced Diabetic Rats Administered with Glutathione Complex for four weeks

\begin{tabular}{|l|l|l|l|l|l|l|}
\hline & GI & GII & GIII & GIV & GV & GVI \\
\hline NoAlx & $85 \pm 1.51$ & $85 \pm 2.51^{\mathrm{a}}$ & $83 \pm 2.60^{\mathrm{a}}$ & $84 \pm 1.09^{\mathrm{a}}$ & $83 \pm 2.44^{\mathrm{a}}$ & $86 \pm 2.68^{\mathrm{a}}$ \\
\hline Alx,48 & $85 \pm 2.19$ & $330 \pm 22.36^{\text {abcdefghi }}$ & $183 \pm 3.96^{\text {abcef }}$ & $214 \pm 17.53^{\text {abcdef }}$ & $285 \pm 14.17^{\text {abcde }}$ & $287 \pm 22.32^{\text {abcdefg }}$ \\
\hline Day3 & $86 \pm 2.19$ & $329 \pm 21.35^{\mathrm{b}}$ & $177 \pm 3.67$ & $200 \pm 17.01$ & $268 \pm 14.17$ & $299 \pm 22.32$ \\
\hline Day6 & $85 \pm 1.09$ & $328 \pm 24.82^{\mathrm{c}}$ & $168 \pm 3.49$ & $187 \pm 15.28$ & $250 \pm 13.51$ & $276 \pm 21.38$ \\
\hline Day9 & $87 \pm 2.19$ & $328 \pm 23.15^{\mathrm{d}}$ & $157 \pm 2.88$ & $174 \pm 14.77$ & $232 \pm 13.38$ & $253 \pm 19.64$ \\
\hline Day12 & $83 \pm 2.60$ & $326 \pm 23.02^{\mathrm{e}}$ & $146 \pm 2.30$ & $160 \pm 13.95^{\mathrm{a}}$ & $214 \pm 12.58$ & $228 \pm 18.75^{\mathrm{b}}$ \\
\hline Day15 & $86 \pm 2.49$ & $327 \pm 23.45^{\mathrm{f}}$ & $135 \pm 2.49^{\mathrm{b}}$ & $145 \pm 13.80^{\mathrm{b}}$ & $195 \pm 12.74^{\mathrm{a}}$ & $204 \pm 18.91^{\mathrm{c}}$ \\
\hline Day18 & $86 \pm 1.79$ & $325 \pm 23.35^{\mathrm{g}}$ & $126 \pm 1.96^{\mathrm{c}}$ & $130 \pm 13.52^{\mathrm{c}}$ & $176 \pm 12.63^{\mathrm{b}}$ & $183 \pm 19.13^{\mathrm{d}}$ \\
\hline Day21 & $84 \pm 1.09$ & $324 \pm 22.05^{\mathrm{h}}$ & $114 \pm 2.88^{\mathrm{d}}$ & $116 \pm 13.24^{\mathrm{d}}$ & $157 \pm 12.54^{\mathrm{c}}$ & $165 \pm 19.11^{\mathrm{e}}$ \\
\hline Day24 & $84 \pm 1.95$ & $323 \pm 20.66^{\mathrm{i}}$ & $104 \pm 2.70^{\mathrm{e}}$ & $102 \pm 11.45^{\mathrm{e}}$ & $139 \pm 12.01^{\mathrm{d}}$ & $146 \pm 17.95^{\mathrm{f}}$ \\
\hline Day27 & $84 \pm 1.34$ & $323 \pm 20.66^{\mathrm{j}}$ & $92 \pm 2.58^{\mathrm{f}}$ & $91 \pm 7.36^{\mathrm{f}}$ & $120 \pm 11.91^{\mathrm{e}}$ & $129 \pm 16.59^{\mathrm{g}}$ \\
\hline
\end{tabular}

Values are mean \pm Standard deviations. Values bearing same superscripts across the groups differ significantly $(\mathrm{P}<0.05)$. Key: $\mathrm{ALX}=$ Alloxan, GI=Group One, GII=Group two, GIII=Group Three, GIV=Group Four, $\mathrm{GV}=$ Group Five, GVI=Group Six.

\section{Discussion}

Alloxan-induced diabetic rat is one of the animal models of human diabetes mellitus. Diabetes arises from irreversible destruction of pancreatic $\beta$-cells, causing degranulation and reduction of insulin secretion (Zhang and Tan, 2000). Alloxan induced diabetes is characterized by hyperglycemia and a severe loss in body weight (Chen and Ianuzzo,1982) and may exhibit most of the diabetic complications such as, myocardial, cardiovascular, gastrointestinal, nervous, kidney and urinary bladder dysfunction through oxidative stress (Rajasekaran et al., 2005). The decrease in body weight in diabetic rats shows that the loss or degradation of structural proteins is due to diabetes, and structural proteins are known to contribute to the body weight (Rajkumar and Govindarajulu, 1991). In diabetes mellitus, there is oxidative stress associated with release of free radicals. Increased oxidative stress in diabetes is also considered as a contributing factor in the development of diabetic complications, including nephropathy, retinopathy (Haskins et al., 2003), and reactive oxygen species generated by high glucose act as a causal link between elevated glucose and the other metabolic abnormalities important in the development of diabetic complications (Brownlee, 2001).

In the present study, blood glucose level in alloxan induced diabetic rats was significantly higher as compared to the normal control rats which may be due to destruction of the $\beta$-cell of pancreas and lead to reduction of insulin secretion, thereby leading to increase in plasma glucose levels and a severe loss of body weight. This finding agrees with the report of Oyedemi et al. (2011), who observed similar effect on diabetic animals treated with streptozotocin (STZ). Therefore, the reduction in body weights may be linked to degradation of structural proteins and increased muscle wasting due to loss of tissue proteins (Daye et al., 2013). Glutathione (GSH), a tripeptide present in all the cells is an important antioxidant. A decreased glutathione level in diabetes has been considered to be an indicator of increased oxidative stress (Lu, 1999). GSH also functions as free radical scavenger and in the repair of radical caused biological damage. A decrease was observed in GSH in liver and kidney during diabetes. The decrease in GSH level represents increased utilization due to oxidative stress (Anuradha and Selvam, 1993).

Administration of Glutathione Complex for four weeks shows some anti-hyperglycemic effect (hypoglycemic effects) in alloxan-induced diabetic rats. When diabetic rats were administered with Glutathione Complex, the weight loss was recovered. The capability of Glutathione Complex to reduce hyperglycemia and protect body weight loss seems to be related to its alpha lipoic acid (ALA), L-cysteine and glutathione (in addition to milk thistle, green tea etc) contents. These compounds may be responsible for it antidiabetic and antioxidant activity, which attributed to its protective action on lipid peroxidation and to the enhancing effect on cellular antioxidant defense contributing to the protection against oxidative damage in alloxanized diabetes. The present finding corroborates the report of Samar et al (2010), who showed that supplementation of ALA significantly reduced STZ induced hyperglycemia in animals with a significant improvement on the body weights of diabetic animals when compared with the control group, which indicated that ALA prevented muscle tissue damage due to diabetic condition. The anti-diabetic activity of ALA has been reported to be due its ability to regulate glucose metabolism (Singh and Jialal, 2008). In addition, Khamaisi et al., (1997) showed that ALA administration to diabetic animals reduced blood glucose concentration by enhancing muscle GLUT4 protein content and thus increased muscle glucose utilization. This present finding was further substantiated by the findings of Vessal et al (2003) who reported that Alpha Lipoic Acid (ALA) serves beneficial effects in decreasing blood glucose concentration, promoting regeneration of the pancreatic islets and increasing insulin release in STZ-diabetic rats. ALA is a potent antioxidant that has effects on fuel metabolism and also acts as an essential cofactor of mitochondrial respiratory 
enzymes, including the pyruvate dehydrogenase (PDH) complex (Nagamatsu et al., 1995). Several studies suggest alpha-lipoic acid helps lower blood sugar levels. Its ability to kill free radicals may help people with diabetic peripheral neuropathy, who have pain, burning, itching, tingling, and numbness in arms and legs from nerve damage (Ibrahimpasic, 2013). Researchers believe Alpha-lipoic acid helps improve insulin sensitivity. Taking alpha-lipoic acid may help another diabetes-related condition called autonomic neuropathy, which affects the nerves to internal organs (Mitkov et al., 2013). Alpha-lipoic acid has been used for years to treat peripheral neuropathy in Germany. One study of 73 people with cardiac autonomic neuropathy, which affects the heart, found that subjects reported fewer signs of the condition when taking $800 \mathrm{mg}$ of alpha-lipoic acid orally (Ibrahimpasic, 2013).

\section{Conclusion}

In conclusion, the current study shows that administration of glutathione complex resulted in a significant hypoglycemic effect during the alterations of impaired blood glucose level and antioxidant status in diabetic condition. Thus, the complex can be recommended for the management of diabetes mellitus.

\section{Reference}

Anuradha, C.V. and Selvam, R. (1993). Effect of oral methionine on tissue lipid peroxidation and antioxidants in alloxan induced diabetic rats, J Nutr Biochem. 4: 212.

Brownlee, M. (2001). Biochemistry and molecular cell biology of diabetic complications. Nature 414: 813 -820.

Chen, V. and Ianuzzo C.D. (1982). Dosage effect of streptozotocin on rat tissue enzyme activities and glycogen concentration. Can J Physiol Pharmacol: 60, pp. 1251-1256

Daye C., Bin, L., Daye C., Bin, L. and Yunhui, L. (2013). Antihyperglycemic Effect of Ginkgo biloba Extract in Streptozotocin-Induced Diabetes in Rats. BioMed Research International. dx.doi.org/10.1155/2013/162724.

Dermazone Trading LLC. (2014) All Rights Reserved. All content on this website www.dermazone.net.

Haskins, K., Bradley, B., Powers, K., Fadok V, Flores, S., Ling, X., Pugazhenthi, S., Reusch, J., and Kench, J. (2003). Oxidative stress in type 1 diabetes. Ann N Y Acad Sci. 1005: 43 -54.

Hokanson, J.E. (2002). Hypertriglyceridemia and risk of coronary heart disease, Curr Cardiol Rep, 4(6):488-493.

Ibrahimpasic, K. (2013). Alpha lipoic acid and glycaemic control in diabetic neuropathies at type 2 diabetes treatment. Med Arh. 67(1):7-9.

IDF (2013). DIABETES ATLAS (6th ed.). International Diabetes Federation. ISBN 2930229853. Pp 7.

Lu, S. C. (1999). Regulation of hepatic glutathione synthesis: Current concepts and controversies, FASEB J, 1169.

Mandrup-Poulsen, T. (1998). Diabetes, Birtish Medical Journal. 316(7139):1221-1225.

Mitkov, M.D., Aleksandrova, I.Y. and Orbetzova, M.M. (2013). Effect of transdermal testosterone or alpha-lipoic acid on erectile dysfunction and quality of life in patients with type 2 diabetes mellitus. Folia Med (Plovdiv). 55(1): 55-63.

Nagamatsu, M., Nickander, K.K., Schmelzer, J.D., Raya, A., Wittrock, D.A., Tritschler, H. and Low, P.A. (1995). Lipoic acid improves nerve blood flow, reduces oxidative stress, and improves distal nerve conduction in experimental diabetic neuropathy, Diabetes Care, 18(8):1160-1167.

Oyedemi, S.O., Yakubu, M.T. and Afolayan, A.J. (2011). Antidiabetic activities of aqueous leaves extract of Leonotis leonurusin streptozotocin induced diabetic rats. Journal of Medicinal Plant Research, 5(1): 119-125.

Rajasekaran, S.K. and Sivagnanam, S. (2005) Subramanian Antioxidant effect of Aloe vera gel extract in streptozotocin-induced diabetes in rats Pharmacol Rep, 57, pp. 90-96.

Rajkumar, P. and Govindarajulu. (1991) Increased degradation of dermal collagen in diabetic rats. Indian J Exp Biol, 29, pp. 1081-1083.

Samar A.A., Shireen A. M. and Hala, A. (2010). Influence of Alpha-Lipoic Acid on Streptozotocin Induced Diabetic Cardiomyopathy in Adult Male Albino Rats: A Biochemical and Microscopical Study. Egypt Journal of Histology, 33(1): 92 -102.

Singh, U. and Jialal I. (2008).Alpha-lipoic acid supplementation and diabetes. Nutrition Reviews. 66(11): 646-657.

Vessal, M., Hemmati, M., and Vasei, M. (2003). Antidiabetic effects of quercetin in streptozotocin-induced diabetic rats, Comp Biochem Physiol Toxicol Pharmacol. 135(3):357-364.

Wiernsperger, N.F. (2003). Oxidative stress as a therapeutic target in diabetes: revisiting the controversy, Diabetes Metab, 29(6):579-585.

Zhang, X.F. Tan, B.K. (2000). Antihyperglycaemic and anti-oxidant properties of Andrographis paniculata in normal and diabetic rats Clin Exp Pharmacol Physiol, 27, pp. 358-363. 